\title{
Erratum to: Characterization of and host response to tyramine substituted-hyaluronan enriched fascia extracellular matrix
}

\author{
LiKang Chin • Anthony Calabro • E. Rene Rodriguez • \\ Carmela D. Tan · Esteban Walker • \\ Kathleen A. Derwin
}

Published online: 18 June 2011

(C) Springer Science+Business Media, LLC 2011

Erratum to: J Mater Sci: Mater Med (2011)

DOI 10.1007/s10856-011-4325-4

The authors inadvertently omitted to mention a correction factor that was used to calculate the HA content of TS-HA

treated fascia. On page 3, second column, line 3, the sentence "A correction factor of 1.53 was applied to the FACE data to correct for the underestimation of dissaccharides in TS-HA preparations, as previously reported [37]." was missed in the original publication.

The online version of the original article can be found under doi:10.1007/s10856-011-4325-4.

L. Chin · A. Calabro · K. A. Derwin ( $₫)$

Department of Biomedical Engineering, Lerner Research Institute, Cleveland Clinic, 9500 Euclid Avenue, ND20,

Cleveland, OH 44195, USA

e-mail: derwink@ccf.org

L. Chin

Department of Biomedical Engineering, Case Western Reserve

University, Cleveland, OH 44106, USA

E. R. Rodriguez $\cdot$ C. D. Tan

Department of Anatomic Pathology, Cleveland Clinic,

Cleveland, OH 44195, USA

E. Walker

Department of Quantitative Health Sciences, Cleveland Clinic,

Cleveland, OH 44195, USA 